\title{
Pre-hospital management, procedural performance and outcomes for primary percutaneous coronary intervention in ST-elevation myocardial infarction in the Netherlands: Insights from the Dutch cohort of the APPOSITION-III trial
}

\author{
N. S. Vos ${ }^{1}$ G. Amoroso ${ }^{1}$ - M. J. Grundeken ${ }^{2}$ A. J. J. Ijsselmuiden ${ }^{3}$ R. J. M. van Geuns ${ }^{4}$ R. Spaargaren ${ }^{5}$ \\ J. G. P. Tijssen ${ }^{2}$ K. T. Koch ${ }^{2}$
}

Published online: 31 August 2016

(C) The Author(s) 2016. This article is available at SpringerLink with Open Access.

\begin{abstract}
Aim The aim of this study was to achieve useful insights into pre-hospital management and procedural performance for ST-elevation myocardial infarction (STEMI) in the Netherlands by extrapolating patient characteristics, and procedural and clinical outcomes of the Dutch patient cohort from the APPOSITION-III trial.

Methods This is a retrospective analysis from the APPOSITION-III trial with respect to the geographical borders of STEMI management. The APPOSITION-III trial was a European registry for the use of the STENTYS self-expandable stent in STEMI patients undergoing primary percutaneous coronary intervention (PPCI). 965 Patients were enrolled mainly in the Netherlands $(n=420,43.5 \%$ of the overall study population), Germany $(n=165)$ and France $(n=131)$. The data from the Dutch cohort were compared with both the overall study population, and the French and German cohorts, respectively, as well as the European Society of Cardiology (ESC) STEMI guidelines.

Results In this trial there was a wide inter-country variation on symptom-to-balloon time, 165 minutes (120-318) in the Netherlands, 270 minutes (180-650) in Germany and 360 minutes (120-480) in France, respectively. In general, a preload of dual antiplatelet therapy (DAPT) combined with heparin was more often performed in the Dutch and
\end{abstract}

G. Amoroso

g.amoroso@olvg.nl

1 Onze Lieve Vrouwe Gasthuis, Amsterdam, The Netherlands

Academic Medical Center, Amsterdam, The Netherlands

Albert Schweitzer Hospital, Dordrecht, The Netherlands

Erasmus Medical Center, Rotterdam, The Netherlands

5 STENTYS S.A., Paris, France
French cohort than in the German cohort. DAPT at discharge was high across the whole APPOSITION-III population. No important differences were seen between the different groups according to the endpoints major adverse cardiac event and stent thrombosis.

Conclusion In the Dutch cohort of an European multicentre STEMI study (APPOSITION-III trial), the performance in terms of symptom-to-balloon time, and pre-, peri- and post-procedural medical treatment is in line with the recommendations of ESC STEMI guidelines.

Keywords ST-elevation myocardial infarction · Primary percutaneous coronary intervention

\section{Introduction}

Primary percutaneous coronary intervention (PPCI) is the recommended treatment for ST-elevation myocardial infarction (STEMI) according to the most recent European Society of Cardiology (ESC) guidelines [1]. The ESC guidelines also make recommendations on appropriateness (symptom-to-balloon time) and standards (concomitant medications) for performing PPCI in STEMI patients [1].

To comply with the ESC guidelines, most European countries have developed national and/or regional networks and protocols for PPCI, and perform quality controls throughout registries. A good example is the Swedish Register of Information and Knowledge about Swedish Heart Intensive Care Admission (RIKS-HIA) [2].

Although the Netherlands was one of the first countries to perform PPCI [3], experiences with local quality assessments are sparse and there is no Dutch national registry to assess clinical performance in STEMI treatment $[4,5]$. 


\section{Advertisement placed here.}

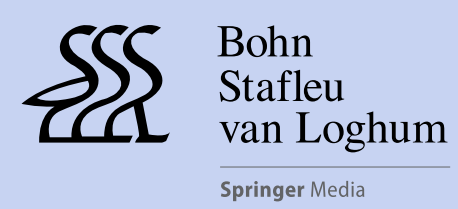

Houten 2016 


\section{Advertisement placed here.}

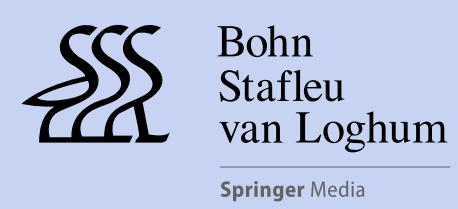

Houten 2016 


\section{Advertisement placed here.}

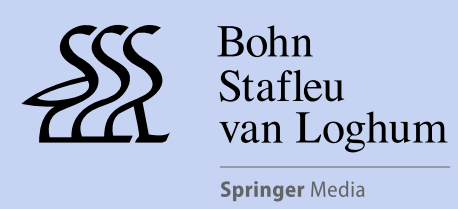

Houten 2016 


\section{Advertisement placed here.}

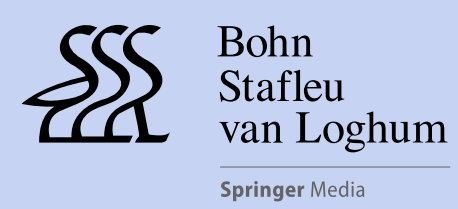

Houten 2016 
In order to achieve useful insights into pre-hospital management and procedural performance for STEMI in the Netherlands, we extrapolated patient characteristics and clinical outcomes of the Dutch patient cohort from a large post-market STEMI study, the APPOSITION-III trial [6], using the overall population and ESC STEMI guidelines as reference.

\section{Methods}

This is a retrospective analysis from the APPOSITION-III trial with respect to the geographical borders of STEMI management. The APPOSITION-III trial was a real-life, prospective, multicentre, European, one-arm, post-market registry for the use of the STENTYS self-expandable stent (STENTYS S.A., Paris, France) in STEMI patients undergoing PPCI. The design and results of the APPOSITIONIII trial have been published in detail previously [6]. This original manuscript provides information about the inclusion and exclusion criteria and study population flow chart. Briefly, patients were eligible for inclusion in the study if they presented with a STEMI caused by a de novo stenosis in a native coronary artery. The primary endpoint was the composite of major adverse cardiac events (MACE) at one-year post-procedure. A total of 965 patients were enrolled in 51 hospitals in 14 European countries, mainly in the Netherlands $(n=420,43.5 \%$ of the overall study population, see appendix A for participating centres in the Netherlands). The remaining patients were enrolled in Germany $(n=165)$, France $(n=131)$, and 11 other European countries. The data from the Dutch cohort were compared with both the overall study population, and the French and German cohorts, respectively.

\section{Statistical analysis}

Continuous variables are presented as mean $( \pm$ standard deviation) if normally distributed or median (interquartile range) in case of not-normal distribution. Categorical variables are presented as frequencies and percentages. Comparisons between groups were performed using oneway ANOVA (normal distributed continuous variables), Kruskal-Wallis (not-normal distributed continuous variables) or Chi-square test (categorical variables), where appropriate. The cumulative event rates in the Dutch subgroup vs. the French and German cohorts were compared using the log-rank test. A $p$-value of $\leq 0.05$ is considered statistically significant. The statistical analyses were performed at the Academic Medical Center (Amsterdam, the Netherlands) using the SPSS software package (version 19.0, IBM, Chicago, IL, USA).

\section{Results}

\section{Baseline demographics and patient characteristics}

The baseline characteristics of the studied groups are summarised in Table 1. There were no differences in mean age and gender. The cardiovascular risk profile of the Dutch patients was similar to the overall population, although the incidence of some of the risk factors was lower compared with the German cohort.

\section{Peri-procedural characteristics}

The general procedural characteristics of the study group are summarised in Table 2 and Fig. 1. There was a wide inter-country variation on symptom-to-balloon time in the APPOSITION-III trial, 165 minutes (120-318) in the

Table 1 Baseline demographics and patient characteristics

\begin{tabular}{|c|c|c|c|c|c|}
\hline Variables & $\begin{array}{l}\text { Netherlands } \\
n=420\end{array}$ & $\begin{array}{l}\text { Germany } \\
n=165\end{array}$ & $\begin{array}{l}\text { France } \\
n=131\end{array}$ & $p$-value & $\begin{array}{l}\text { Total study population } \\
n=965\end{array}$ \\
\hline Age (years) & $59 \pm 12$ & $62 \pm 12$ & $59 \pm 13$ & 0.083 & $60 \pm 12$ \\
\hline Male gender $(\%)$ & $317(76)$ & $125(76)$ & $107(82)$ & 0.325 & $743(77)$ \\
\hline Diabetes mellitus (\%) & $52(12)$ & $37(22)$ & $18(14)$ & 0.008 & $140(15)$ \\
\hline Hypertension (\%) & $161(38)$ & $116(70)$ & $51(39)$ & $<0.0001$ & $456(47)$ \\
\hline Hypercholesterolaemia (\%) & $120(29)$ & $93(56)$ & $56(43)$ & $<0.0001$ & $404(42)$ \\
\hline Current smoking $(\%)$ & $240(57)$ & $83(50)$ & $79(60)$ & 0.185 & $539(56)$ \\
\hline Family history of CAD (\%) & $199(47)$ & $46(28)$ & $38(29)$ & $<0.0001$ & $360(37)$ \\
\hline Previous MI (\%) & $23(5.5)$ & $10(6.1)$ & $2(1.5)$ & 0.003 & $46(4.8)$ \\
\hline Previous PCI (\%) & $28(6.7)$ & $11(6.7)$ & $3(2.3)$ & 0.156 & $54(5.6)$ \\
\hline Previous CABG (\%) & $2(0.5)$ & 0 & $1(0.8)$ & 0.577 & $3(0.3)$ \\
\hline Previous stroke (\%) & $14(3.3)$ & $2(1.2)$ & $6(4.6)$ & 0.085 & $25(2.6)$ \\
\hline
\end{tabular}

$C A D$ coronary artery disease, $M I$ myocardial infarction, $P C I$ percutaneous coronary intervention, $C A B G$ coronary artery bypass graft 
Table 2 Peri-procedural characteristics

\begin{tabular}{llllll}
\hline Variable & $\begin{array}{l}\text { Netherlands } \\
n=420\end{array}$ & $\begin{array}{l}\text { Germany } \\
n=165\end{array}$ & $\begin{array}{l}\text { France } \\
n=131\end{array}$ & $\begin{array}{l}p \text {-value } \\
\text { Total study population } \\
n=965\end{array}$ \\
\hline $\begin{array}{l}\text { Symptom onset to balloon time (min) } \\
\text { TIMI flow culprit vessel pre-procedure }\end{array}$ & $165(20-318)$ & $270(120-615)$ & $360(180-660)$ & $<0.0001$ & $210(120-480)$ \\
0 & $229(55 \%)$ & $92(56 \%)$ & $92(56 \%)$ & - & - \\
1 & $54(13 \%)$ & $33(20 \%)$ & $33(20 \%)$ & - & $551(57 \%)$ \\
2 & $78(19 \%)$ & $27(16 \%)$ & $27(16 \%)$ & - & $127(13 \%)$ \\
3 & $54(13 \%)$ & $13(8 \%)$ & $13(7.9 \%)$ & - & $162(17 \%)$ \\
TIMI flow culprit vessel post-procedure & & & & 0.5001 & - \\
0 & $4(1.0 \%)$ & $4(2.4 \%)$ & 0 & - & $120(13 \%)$ \\
1 & $1(0.2 \%)$ & $1(0.6 \%)$ & $1(0.8 \%)$ & - & $4(0.40 \%)$ \\
2 & $16(3.8 \%)$ & $8(4.8 \%)$ & $5(3.8 \%)$ & - & $39(4 \%)$ \\
3 & $397(95 \%)$ & $152(92 \%)$ & $125(95 \%)$ & - & $910(95 \%)$ \\
\hline
\end{tabular}

TIMI Thrombolysis In Myocardial Infarction

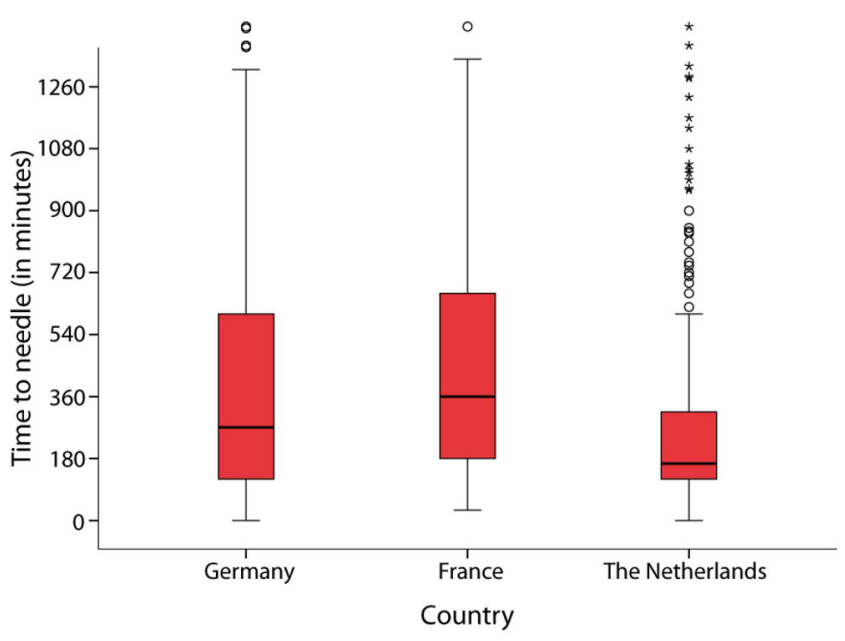

Fig. 1 Time to needle per country

Netherlands, 270 minutes (120-615) in Germany and 360 minutes (180-660) in France, respectively. At initial angiography and afterwards, TIMI flow grade 3 in the infarctrelated vessel was comparable for all subgroups.

\section{Medication use}

The use of medication pre-hospital (in the ambulance), periprocedural and at discharge is shown in Table 3. The Dutch patients in the APPOSITION-III trial had been preloaded with acetylsalicylic acid and a P2Y12 inhibitor, in 97 and $93 \%$ of the cases, respectively, and with unfractionated heparin in $94 \%$ of cases. In general, this treatment regimen was more often performed in the Netherlands and France than in Germany. The dual antiplatelet therapy at discharge was high across the whole APPOSITION-III trial.
Major adverse cardiac events and stent thrombosis

The endpoints MACE and stent thrombosis at 30 days and one-year follow-up are shown in Table 4. No important differences were seen between the different groups according these endpoints.

\section{Discussion}

Despite the fact that reperfusion therapies, in particular PPCI, have proven substantial effectiveness in clinical trials, worldwide mortality from STEMI outside clinical trials remains high [7]. In developing countries, both an increasing incidence of risk factors for coronary artery disease and multiple shortcomings in health policies and therapeutic options can be responsible for a higher mortality $[8,9]$. Even within Europe, there is a wide inter-country variability in patient characteristics, use of medication and invasive procedures in STEMI patients [10, 11].

In 2007, for instance, only 40-45\% of European STEMI patients were treated with PPCI [12]. Especially in the southern and eastern countries thrombolysis was the preferred strategy. In northern, western and central Europe, PPCI was offered to $60-90 \%$ of the STEMI patients [12]. Among all European countries, the Netherlands is expected to apply best-practice treatment for STEMI, because of the universal and well-developed healthcare system, the modern logistics and infrastructures, and the percentage of gross product invested in healthcare $[11,13]$. Historically, the first study suggesting the advantages of PPCI vs. conventional treatment was indeed performed in the Netherlands in the early $1990 \mathrm{~s}$ [3]. Despite all these assets, it is at present not possible to assess national performance for STEMI in the Netherlands because a national registry is not available.

By virtue of the large number of Dutch patients enrolled, the APPOSITION-III trial offers a good opportunity for 
Table 3 Medication use

\begin{tabular}{|c|c|c|c|c|c|}
\hline Variable & Netherlands (\%) & Germany $(\%)$ & France $(\%)$ & $p$-value & Total study population (\%) \\
\hline \multicolumn{6}{|l|}{ Pre-procedure (in ambulance) } \\
\hline Acetylsalicylic acid & $375 / 407(92)$ & $134 / 165(81)$ & $118 / 131(90)$ & 0.001 & $838 / 950(88)$ \\
\hline P2Y12 inhibitor & $331 / 407(81)$ & $89 / 165(54)$ & $108 / 131(82)$ & $<0.00001$ & $709 / 950(75)$ \\
\hline Heparin & $300 / 407(74)$ & $76 / 165(46)$ & $66 / 131(50)$ & $<0.00001$ & $574 / 950(60)$ \\
\hline \multicolumn{6}{|l|}{ Pre-and/or peri-procedure } \\
\hline Acetylsalicylic acid & 393/407 (97) & $154 / 165(93)$ & $125 / 131(95)$ & 0.233 & $897 / 950(94)$ \\
\hline P2Y12 inhibitor & $380 / 407(93)$ & $131 / 165(79)$ & $124 / 131(95)$ & $<0.00001$ & $863 / 950(91)$ \\
\hline Heparin & $381 / 407(94)$ & $154 / 165(93)$ & $89 / 131(68)$ & $<0.00001$ & $825 / 950(87)$ \\
\hline Bivalirudin & $46 / 407(11)$ & $1 / 165(1)$ & $3 / 131(2)$ & $<0.00001$ & $109 / 950(12)$ \\
\hline Glycoprotein IIb/IIIa inhibitor & $147 / 407(36)$ & $60 / 165(36)$ & $59 / 131(45)$ & 0.169 & $357 / 950(38)$ \\
\hline \multicolumn{6}{|l|}{ Discharge } \\
\hline Acetylsalicylic acid & $408 / 418(98)$ & $162 / 165(98)$ & $128 / 130(99)$ & 0.804 & $941 / 960(98)$ \\
\hline P2Y12 inhibitor & $418 / 418(100)$ & $162 / 165(98)$ & $130 / 130(100)$ & 0.007 & $954 / 960(99)$ \\
\hline On DAPT & $408 / 418(98)$ & $162 / 165(98)$ & $128 / 130(99)$ & 0.804 & 939/960 (98) \\
\hline
\end{tabular}

$D A P T$ dual antiplatelet therapy

Table 4 Major adverse cardiac events and stent thrombosis at 30 days and one-year follow-up

\begin{tabular}{|c|c|c|c|c|c|c|c|c|c|}
\hline \multirow[b]{2}{*}{ Events at 30 days } & \multicolumn{2}{|c|}{$\begin{array}{l}\text { Netherlands } \\
n=420\end{array}$} & \multicolumn{2}{|l|}{$\begin{array}{l}\text { Germany } \\
n=165\end{array}$} & \multicolumn{2}{|l|}{$\begin{array}{l}\text { France } \\
n=131\end{array}$} & \multirow{2}{*}{$\begin{array}{l}p \text {-value } \\
-\end{array}$} & \multicolumn{2}{|c|}{$\begin{array}{l}\text { Total study population } \\
n=965\end{array}$} \\
\hline & Patients & $\begin{array}{l}\text { Event rate* } \\
\text { (percentage) }\end{array}$ & Patients & $\begin{array}{l}\text { Event rate* } \\
\text { (percentage) }\end{array}$ & Patients & $\begin{array}{l}\text { Event rate* } \\
\text { (percentage) }\end{array}$ & & Patients & $\begin{array}{l}\text { Event rate } \\
\text { (percentage) }\end{array}$ \\
\hline MACE & 18 & 4.3 & 5 & 3.1 & 0 & - & 0.053 & 34 & 3.5 \\
\hline Definite/probable ST & 17 & 4.1 & 5 & 3.1 & 0 & - & 0.066 & 30 & 3.1 \\
\hline - Definite ST & 15 & 3.6 & 3 & 1.8 & 0 & - & 0.061 & 24 & 2.5 \\
\hline - Probable ST & 2 & 0.5 & 2 & 1.2 & 0 & - & 0.350 & 6 & 0.6 \\
\hline Events at one-year & Patients & $\begin{array}{l}\text { Event rate* } \\
\text { (percentage) }\end{array}$ & Patients & $\begin{array}{l}\text { Event rate* } \\
\text { (percentage) }\end{array}$ & Patients & $\begin{array}{l}\text { Event rate* } \\
\text { (percentage) }\end{array}$ & - & Patients & $\begin{array}{l}\text { Event rate } \\
\text { (percentage) }\end{array}$ \\
\hline MACE & 32 & 7.7 & 21 & 12.7 & 12 & 9.2 & 0.112 & 86 & 8.9 \\
\hline Definite/probable ST & 17 & 4.1 & 6 & 3.6 & 0 & - & 0.070 & 33 & 3.5 \\
\hline - Definite ST & 15 & 3.6 & 4 & 2.4 & 0 & - & 0.085 & 27 & 2.8 \\
\hline - Probable ST & 2 & 0.5 & 2 & 1.2 & 0 & - & 0.350 & 6 & 0.6 \\
\hline
\end{tabular}

*Kaplan-Meier estimates. $P$-value with log rank test

MACE major adverse cardiac events (defined as the composite of cardiac death, recurrent target-vessel related myocardial infarction and clinically-driven target lesion revascularization), $S T$ stent thrombosis

studying management of STEMI patients in the Netherlands [6], at a time when ESC STEMI guidelines had already been published.

According to the ESC STEMI guidelines, restoring coronary flow in the infarct-related vessel and myocardial tissue reperfusion are of major prognostic importance [1]. A shorter time between the occurrence of ischaemia and the achievement of reperfusion results in improved myocardial salvage and is associated with better clinical outcomes [14]. Therefore, in patients presenting with STEMI, pharmacological and/or mechanical (PCI) reperfusion should be performed as early as possible $[1,15]$. Besides system delay, symptom duration may accurately reflect the risk not only of myocardial injury but also long-term mortality as suggested in a recently published analysis of the HORI-
ZONS-AMI trial [16]. In the APPOSITION-III trial, the symptom-to-balloon time shows huge differences between the three studied cohorts and the overall population, with better performance in the Dutch cohort. These differences can only partly be explained by a more favourable geography (shorter distances) and infrastructure (more highways) in the Netherlands. Patient awareness of symptoms, fast response of the emergency services (ambulance) and direct referral to tertiary PCI-capable hospitals by an ECG transfer system (from ambulance to PCI centre) probably play a major role [13].

The results of the Dutch cohort of the APPOSITION-III trial closely resembled those of another, albeit randomised, STEMI study: the ATLANTIC trial. The ATLANTIC trial is a multicentre, international, double-arm, double-blind, 
randomised study comparing the uploading of ticagrelor in the ambulance or at the cathlab in STEMI patients undergoing PPCI [17]. Of the overall 1862 patients, only $7.9 \%$ came from the Netherlands, while the rest were enrolled in 12 other European countries. The average symptom-toballoon time of the Dutch patients in the APPOSITIONIII trial is 165 minutes, which is almost similar to the 159 minutes in the ATLANTIC trial. First-medical-contact-toballoon (FMCTB) time, i.e. the symptom-to-balloon minus the symptom-to-first-medical-contact time, which is an index of system delay, was on average 86 minutes in the ATLANTIC trial. Adams et al. [13] have reported that this is also comparable with the Dutch situation, at least for the Great Amsterdam Area. We can speculate that in the Netherlands real-life STEMI patients already receive the treatment that is recommended (Class IA) by the ESC for PPCI standard of performance (FMCTB time $<90 \mathrm{~min}$ in $80 \%$ of the population), while perhaps in other European countries this is only achievable in highly selected, strongly monitored randomised trials. In 2008, the ESC launched the Stent for Life initiative in order to implement effective PPCI programs and achieve the same results in all its 47 member countries across Europe and the Mediterranean basis [11].

Another important factor influencing the restoration of coronary flow in the infarct-related vessel and related myocardial tissue reperfusion is the routine use of peri-procedural dual antiplatelet (DAPT) (Class $1 \mathrm{~A}$ ) and antithrombotic medication such as unfractionated heparin (Class $1 \mathrm{C}$ ). The analysis of the Dutch subgroup of the AppositionIII trial shows adequate peri- and post-procedural medical treatment in $95 \%$, and $98 \%$ at discharge, respectively. In particular, the comparison of the preloading strategy with the German cohort shows important differences in the APPOSITION-III trial.

Although our retrospective analysis let some differences emerge in the management of STEMI patients between the Netherlands and other European countries, this had no significant impact on MACE at 30 days and one-year followup. The reason for this lack of effect is uncertain and contradictory with other previous studies, but the explanations could include a lack of power for MACE, a lack of prospectively registered surrogate outcomes and limited follow-up at this moment [13]. Most likely the higher occurrence of specific device-related events (stent thrombosis at 30 days follow-up in the APPOSITION-III was $3.1 \%$, while in the Atlantic was $2.2 \%$, for instance), as well as the disproportion in geographical inclusion, and possible selection bias in the least including countries, could have overshadowed the effect of earlier reperfusion.

Therefore, although the data from the Dutch cohort from the APPOSITION-III trial are reassuring, it will be impossible without a national STEMI registry to draw definitive conclusions on whether treatment performances are ade- quate for each Dutch patient presenting with STEMI. Both the National Cardiovascular Data Registry (NCDR) and the NVVC Connect projects, the first aimed at creating a national database, and the second at promoting local networks, will soon shed more light on this subject [18, 19].

\section{Limitations}

As already mentioned, the Dutch population described in this study was retrospectively extracted from a multicentre, albeit all-comers, registry. Due to an inclusion bias (partly consecutive enrolment) and the limited amount of patients included, this study cannot be considered a true epidemiological study, but merely a snapshot with possible clinical implications. Moreover, the APPOSITION-III trial was performed in teaching and university hospitals, which may not entirely represent the reality of any country as a whole. Time to first medical contact, as well as door-toballoon time are important parameters for quality assessment in STEMI. Neither of these data were captured in the APPOSITION-III study; therefore we can only indirectly extrapolate the Dutch performance on so-called 'system delay'.

\section{Conclusion}

In the Dutch cohort of an European multicentre STEMI study (APPOSITION-III trial), the performance in terms of symptom-to-balloon time, and pre-, peri- and post-procedural medical treatment matches the recommendation of ESC STEMI guidelines.

Acknowledgements All the Investigators of the APPOSITION-III trial.

Funding None.

Conflict of interest N.S. Vos, G. Amoroso, M.J. Grundeken, A.J.J. Ijsselmuiden, R.J.M. van Geuns, R. Spaargaren, J.G.P. Tijssen and K.T. Koch state that they have no competing interest.

Open Access This article is distributed under the terms of the Creative Commons Attribution 4.0 International License (http:// creativecommons.org/licenses/by/4.0/), which permits unrestricted use, distribution, and reproduction in any medium, provided you give appropriate credit to the original author(s) and the source, provide a link to the Creative Commons license, and indicate if changes were made. 


\section{Appendix A}

\section{Participating centres}

\section{The Netherlands}

- Onze Lieve Vrouwe Gasthuis (Amsterdam): 100 patients $(23.8 \%)$

- Academic Medical Center (Amsterdam): 100 patients $(23.8 \%)$

- Albert Schweitzer Hospital (Dordrecht): 89 patients (21.2\%)

- Erasmus Medical Center (Rotterdam): 63 patients (15\%)

- St. Antonius Hospital (Nieuwegein): 38 patients (9\%)

- VU Medical Center (Amsterdam): 17 patients (4\%)

- Scheper Hospital (Emmen): 8 patients (1.9\%)

- Amphia Hospital (Breda): 5 patients (1.2\%)

\section{Germany}

- SLK-Kliniken Heilbronn (Heilbronn)

- Evang. Bethesda Johanniter (Duisburg)

- Klinikum Neuperlach (Munich)

- Elisabeth-Krankenhaus (Essen)

- Klinikum Coburg

- Universitätsklinikum Giessen und Marburg

- Herz- und Diabeteszentrum NRW (Bad Oeynhausen)

- Klinikum der Universität (Munich)

- Klinikum Bogenhausen

\section{France}

- CHU La Pitié-Salpêtrière (Paris)

- Clinique Saint-Hilaire (Rouen)

- Institut Hospitalier Jacques Cartier (Massy)

- CHU Henri Mondor (Créteil)

- Centre Cardioloque d'Evecquemont

- Clinique de l'Europe (Amiens)

- La Roseraie (Aubervilliers)

- Centre Hospitalier Victor Dupouy (Argenteuil)

\section{References}

1. Task Force on the management of ST-segment elevation acute myocardial infarction of the European Society of Cardiology (ESC). ESC Guidelines for the management of acute myocardial infarction in patients presenting with ST-segment elevation. Eur Heart J. 2012;33:2569-619.

2. Björck L, Wallentin L, Stenestrand U, Lappas G, Rosengren A. Medication in relation to ST-segment elevation myocardial infarc- tion in patients with a first myocardial infarction: Swedish Register of Information and Knowledge About Swedish Heart Intensive Care Admissions (RIKS-HIA). Arch Intern Med. 2010;170:1375-81.

3. Zijlstra F, de Boer MJ, Hoorntje JC, Reiffers S, Reiber JH, Suryapranata H. A comparison of immediate coronary angioplasty with intravenous streptokinase in acute myocardial infarction. $\mathrm{N}$ Engl J Med. 1993;328:680-4.

4. Meetbaar beter. Available at: http://www.meetbaarbeter.com/wpcontent/uploads/2014/12/507397_MeetbaarBeter_Compleet.pdf. Accessed 29 Aug 2016.

5. Verweij LM, Tra J, Engel J, et al. Data quality issues impede comparability of hospital treatment delay performance indicators. Neth Heart J. 2015;23:420-7.

6. Koch KT, Grundeken MJ, Vos NS, et al. One-year clinical outcomes of the STENTYS self-apposing coronary stent in patients presenting with ST-segment elevation myocardial infarction: results from the APPOSITION III registry. EuroIntervention. 2015;11:264-71.

7. Mackay J, Mensah G. (editors) Atlas of heart disease and stroke. Geneva: World Health Organization; 2004, http://www.who.int/ cardiovascular_diseases/resources/atlas/en/index.html.

8. Gaziano TA. Cardiovascular disease in the developing world and its cost-effective management. Circulation. 2005;112:3547-53.

9. Gaziano TA, Bitton A, Anand S, et al. Growing epidemic of coronary heart disease in low- and middle-income countries. Curr Probl Cardiol. 2010;35:72-115.

10. Yusuf F, Flather M, Pogue J, et al. Variations between countries in invasive cardiac procedures and outcomes in patients with suspected unstable angina or myocardial infarction without initial ST elevation. Lancet. 1998;352:507-14.

11. Widimsky P, Fajadet J, Danchin N, Wijns W. "Stent 4 Life" targeting PCI at all who will benefit the most. A joint project between EAPCI, Euro-PCR, EUCOMED and the ESC Working Group on Acute Cardiac Care. EuroIntervention. 2009;4(5):555-7.

12. Widimsky P, Wijns W, Fajadet J, et al. Reperfusion therapy for ST elevation acute myocardial infarction in Europe: description of the current situation in 30 countries. Eur Heart J. 2010;31:943-57.

13. Adams R, Appelman Y, Bronzwaer JG, et al. Implementation of a prehospital triage system for patients with chest pain and logistics for primary percutaneous coronary intervention in the region of Amsterdam, the Netherlands. Am J Cardiol. 2010;106:931-5.

14. Berger PB, Ellis SG, Holmes DR, et al. Relationship between delay in performing direct coronary angioplasty and early clinical outcome in patients with acute myocardial infarction: results from the global use of strategies to open occluded arteries in acute coronary syndromes (GUSTO-IIb) trial. Circulation. 1999;100:14-20.

15. De Boer MJ, Zijlstra F. STEMI time delays: a clinical perspective. Neth Heart J. 2015;23:415-9.

16. Prasad A, Gersh BJ, Mehran R, et al. Effect of ischemia duration and door-to-balloon time on myocardial perfusion in STsegment elevation myocardial infarction: an analysis from HORIZONS-AMI trial (harmonizing outcomes with revascularization and stents in acute myocardial infarction). JACC Cardiovasc Interv. 2015;8:1966-74.

17. Montalescot G, van 't Hof AW, Lapostolle F, et al. Prehospital ticagrelor in ST-segment elevation myocardial infarction. N Engl J Med. 2014;371:1016-27.

18. National Cardiovascular Data Registry; ACS. Available at: http:// www.ncdr.nl/registraties/acs/. Accessed 29 Aug 2016.

19. Westra K, editors. NVVC Connect 2014; project acuut hartinfarct. Available at: http://www.nvvcconnect.nl/images/jaarverslag/ jaarverslag_Connect_2014.pdf. Accessed 29 Aug 2016. 